\title{
Comportamento morfossintático e pragmático do muito embora
}

\author{
Vanessa Pereira Abreu ${ }^{1}$
}

\section{Resumo}

O principal objetivo desta pesquisa é investigar o comportamento morfossintático e pragmático do muito embora, através da análise quantitativa e qualitativa de 50 dados do muito embora e, por oposição, de 50 dados do embora extraídos do Córpus Brasileiro Eletrônico da PUC de São Paulo, com base no funcionalismo linguístico de vertente norte-americana (GIVÓN, 2012[1979]). Resultados indicam que o muito embora ocorre em uma oração/construção posposta à oração principal, com presença de verbo no modo subjuntivo. Em contraposição, a oração/construção com o embora apresenta uma menor frequência de posposição, ainda que essa posição sintática seja recorrente; permite a ausência de verbo, e quando usado, aparece em diferentes formas (nominal e conjugada). No que se refere ao comportamento pragmático, ambos, muito embora e embora, assumem o propósito de cancelar uma inferência atribuída ao interlocutor. É importante que se reconheça a heterogeneidade linguística para a compreensão das diferentes situações de comunicação.

Palavras-chave: muito embora; comportamento morfossintático; comportamento pragmático

\begin{abstract}
The main objective of this research is to investigate the morphosyntactic and pragmatic behavior of muito embora, through quantitative and qualitative analysis of 50 data of muito embora and, by contrasting with 50 data of embora extracted from Córpus Brasileiro Eletrônico (Brazilian Electronic Corpus) of PUC University from São Paulo, based on linguistic role through a North-American aspect (Givón, 2012[1979]). The results have indicated that muito embora tends to occur postponed of the main clause with the specific presence of a subjunctive verb. In contrast, the embora clause presents a lower frequency of postposition, even though it's syntactic position is more frequent. Also, it allows the absence of the verb, and when used, appears in different forms, such as nominal and conjugated forms of verbs. With regard to the pragmatic behavior, both, muito embora and embora assume the purpose of cancelling the inference assigned to the interlocutor. It is important to recognize the linguistic diversity to understand the different communication situations.
\end{abstract}

Key-words: muito embora; morphosyntactic behavior; pragmatic behavior

\footnotetext{
${ }^{1}$ Especialista em Linguística e Ensino de Língua Portuguesa. Universidade Federal do Rio Grande (FURG). Instituto de Letras e Artes (ILA). Curso de Pós-Graduação Lato Sensu em Linguística e Ensino de Língua Portuguesa (PGLING). Rio Grande. Rio Grande do Sul. Brasil. E-mail: vanessaabreu.letras@gmail.com
}

Revista Leitura V.2 no 56 - jul/dez 2015 - Número regular - Autor/a: Vanessa Pereira Abreu - p. 153 - 172. 


\section{Introdução}

O objeto de estudo investigado nesta pesquisa centra-se na análise do comportamento morfossintático e pragmático do muito embora a partir da análise de dados extraídos do Córpus ${ }^{2}$ Brasileiro da PUC de São Paulo ${ }^{3}$. O estudo tem como base inicial a consulta a gramáticas normativas (BECHARA, 2009; CEGALLA, 2005; CUNHA; CINTRA, 2007) e de uso (AZEREDO, 2000; NEVES, 2000; PERINI, 2006) e está embasado no funcionalismo linguístico norte-americano de Givón (2012[1979]) e em autores como Kenedy e Martelotta (2003), Martelotta (1998), Castilho (2012) e Cezario (2012).

A escolha do objeto de estudo foi motivada por ocasião de uma das reprises das sessões da Câmara do Rio Grande, no mês de junho de 2013, no Canal 4 da Via Cabo TV, em que uma das vereadoras da cidade usou o muito embora em seu discurso na tribuna. Em outra ocasião, no texto "Manifestações Populares", publicado no Jornal Agora $^{4}$ e enviado pelo Servidor Público Federal Júlio César Berchon Des Essarts para o Caderno Opinião (Carta do Leitor, 20/06/2013), o fenômeno reaparece. Soma-se a essas motivações o fato de ter encontrado somente um trabalho publicado, de autoria da Felício (2008), que trata do uso do muito embora ${ }^{5}$, ainda que de forma parcial.

Nesse sentido, o objetivo principal é investigar o comportamento morfossintático e pragmático do muito embora, no córpus eletrônico, com base no funcionalismo linguístico de vertente norte-americana, confrontando seu uso com o do embora.

Algumas questões norteiam esta pesquisa:

1) As gramáticas normativas e de uso mencionam o muito embora?

Acredita-se que as gramáticas normativas não abordam o fenômeno investigado, considerando a perspectiva mais prescritivista; diferentemente, espera-se que as gramáticas de uso façam algum tipo de referência.

2) Qual a configuração morfossintática do muito embora?

\footnotetext{
${ }^{2}$ Neste artigo, a palavra córpus está acentuada, seguindo as regras de acentuação para as palavras terminadas em us no português do Brasil.

${ }^{3}$ Disponível em: <http://corpusbrasileiro.pucsp.br/cb/Inicial.html >

${ }^{4}$ Jornal de circulação na cidade do Rio Grande - RS.

${ }^{5}$ É possível que haja outras publicações a respeito, porém não foram encontradas em diferentes buscas realizadas na internet.

Revista Leitura V.2 nº 56 - jul/dez 2015 - Número regular - Autor/a: Vanessa Pereira Abreu - p. 153 - 172.
} 
Com base na análise de alguns dados, acredita-se que o muito embora apresente mais posposição em relação à oração principal, configurando o mesmo esquema regular relacionado ao embora (NEVES, 2000). Soma-se o uso do verbo do subjuntivo, muito associado ao embora por Cegalla (2005) e Cunha e Cintra (2007).

3) Qual a importância pragmática do muito embora?

Acredita-se que o muito embora assuma o mesmo propósito do embora: o falante faz asseverações e, depois, "pesa objeções, utilizando-as, de certo modo, na defesa do ponto de vista expresso" (NEVES, 2000, p. 878).

4) Seria o muito embora um conector?

Considerando as semelhanças entre o comportamento morfossintático e pragmático do muito embora com o embora, acredita-se que possa ser considerado um conector.

Dessa forma, o presente trabalho está assim organizado: a segunda seção trata da revisão do objeto, que inclui análise das gramáticas normativas e de uso, sob um enfoque das orações/construções adverbiais, dos conectores subordinativos adverbiais e, finalmente, dos advérbios. A terceira seção delineia o referencial teórico, que aborda, em linhas gerais, a teoria funcionalista de vertente norte-americana. Na sequência, estão os procedimentos metodológicos; e, na seção seguinte, a análise e discussão dos dados. Por fim, seguem-se as considerações finais.

\section{Revisão do objeto}

Nesta seção, apresenta-se uma revisão de algumas gramáticas normativas e de uso acerca do fenômeno em análise, especificamente no que concerne à oração/construção adverbial concessiva, ao conector concessivo e ao advérbio. A primeira subseção tem o objetivo de verificar menções em relação ao muito embora sob a visão de algumas gramáticas normativas (BECHARA, 2009; CEGALLA, 2005; CUNHA; CINTRA, 2007), e a segunda subseção, de gramáticas de uso (AZEVEDO, 2000; NEVES, 2000; PERINI, 2006). Na terceira subseção, uma breve resenha das pesquisas desenvolvidas por Felício (2008) e Margarido (s/d) é apresentada.

\section{Gramática normativa}

Revista Leitura V.2 nº 56 - jul/dez 2015 - Número regular - Autor/a: Vanessa Pereira Abreu - p. 153 - 172. 
A gramática normativa trata do padrão culto escrito da língua, ditando regras e conceitos preestabelecidos. Madeira afirma que:

a gramática normativa lida com os fatos da língua padrão, da norma culta da língua. Neste modelo gramatical, a importância maior é dada à língua escrita - na verdade, a variedade oral da norma culta nem é diferenciada da escrita. A gramática normativa (também chamada de tradicional) dita leis (normas) para o uso da língua: não aceita considera "erro" - o uso de quaisquer outras formas diferentes da norma culta da língua (que se tornou oficial) (MADEIRA, 2005, p. 22).

As orações/construções ${ }^{6}$ subordinadas adverbiais têm a função dos adjuntos adverbiais de orações principais e são introduzidas pelos conectores subordinativos ${ }^{7}$ (BECHARA, 2009; CEGALLA, 2005; CUNHA; CINTRA, 2007). Bechara (2009, p. 496) destaca que a oração subordinada adverbial concessiva ocorre "quando a subordinada exprime que um obstáculo - real ou suposto - não impedirá ou modificará de modo algum a declaração da oração principal”.

Cegalla (2005, p. 291) afirma que "as conjunções subordinativas ligam duas orações, subordinando uma à outra [...]" e que elas "iniciam orações que traduzem circunstâncias [...]". De acordo com Cunha e Cintra (2007, p. 600), "as conjunções subordinativas [...] iniciam orações adverbiais".

No que se refere ao advérbio de intensidade muito, afirma-se que pode exercer a função sintática de adjunto adverbial (CEGALLA, 2005; BECHARA, 2009) e ainda pode "reforçar o sentido de um adjetivo e de um advérbio" (CUNHA; CINTRA, 2007, p. 555-556). Para Cegalla (2005), o advérbio modifica o verbo e exprime uma circunstância, porém somente os advérbios de intensidade podem modificar os adjetivos e os advérbios. Já Bechara (2009) reconhece o advérbio, de forma geral, como um intensificador do verbo, do adjetivo ou até de um enunciado inteiro.

Com base na breve apresentação da oração/construção subordinada concessiva, do conector concessivo e do advérbio muito, pode-se afirmar que as gramáticas

\footnotetext{
${ }^{6}$ As gramáticas normativas não fazem referência à palavra "construções", porém a "adjunto adverbial", no caso, de concessão.

${ }^{7}$ Neste trabalho, opta-se pela seguinte terminologia: conector subordinativo concessivo e não conjunção subordinativa concessiva. O primeiro abarca a divisão apresentada em muitas gramáticas tradicionais entre conjunção e locução conjuntiva.

Revista Leitura V.2 nº 56 - jul/dez 2015 - Número regular - Autor/a: Vanessa Pereira Abreu - p. 153 - 172.
} 
normativas consultadas não consideram o muito embora como conector e nem fazem menção sobre a sua existência.

\section{Gramática de uso}

Diferentemente da perspectiva da gramática normativa,

a gramática descritiva, por sua vez, corresponde a um conjunto de regras baseado no uso da língua. [...] Sob a perspectiva da gramática descritiva, o erro gramatical não existe, ou, melhor explicando, caracteriza-se (sic) como um "erro" apenas as formas ou estruturas que fogem ao funcionamento das diversas variedades de uma língua. Assim, usos da língua que não eram aceitos pela gramática normativa passam a ser aceitos pela descritiva (POSSENTI, 1996 apud MADEIRA, 2005, p. 23).

Segundo essa definição, a gramática de uso se preocupa com as regras percebidas no uso efetivo da língua, conforme ilustra a revisão realizada nas obras de Perini (2006), Azeredo (2000) e Neves (2000) na tentativa de identificar menções ao fenômeno em análise.

Perini (2006) considera a oração subordinada como aquela que é parte de outra oração, completando o seu sentido. De acordo com Azeredo (2000, p. 222), "as orações adverbiais funcionam principalmente como adjuntos de outras orações [...]" assim como nas gramáticas normativas.

De acordo com Neves (2000), a oração/construção ${ }^{8}$ concessiva pode, portanto, introduzir um enunciado e, ao mesmo tempo, pode funcionar na oração subordinada, dando ideia de contrariedade. Equivale dizer que, na oração/construção concessiva, é dada mais ênfase à noção expressa na oração principal. Nesse sentido, "o que ocorre numa construção concessiva é que uma pretensa causa (ou uma condição) é expressa na oração concessiva, mas aquilo que dela se pode esperar é negado na oração principal" (NEVES, 2000, p. 868).

Neves (2000, p. 878) menciona que, "nas construções concessivas [...], tanto ocorre posposição como anteposição, e, mesmo, intercalação da oração concessiva". E ainda destaca que "é mais frequente a posposição da concessiva, já que é bastante

\footnotetext{
${ }^{8}$ Neves (2000) chama de construção toda oração ou conjunção concessiva. Revista Leitura V.2 nº 56 - jul/dez 2015 - Número regular - Autor/a: Vanessa Pereira Abreu - p. 153 - 172.
} 
regular o seguinte esquema: i) primeiro se expressa a asserção nuclear; e ii) depois se expressa a objeção".

E ainda nas orações concessivas, Neves (2000, p. 878) aborda que "facilmente se verifica que as orações concessivas antepostas carregam informação mais conhecida do interlocutor, ocupando uma posição mais tópica", como no exemplo (1):

(1) Muito embora todos, ou quase todos, os conceitos acima emitidos sejam admissíveis, impõe-se uma recolocação do problema (NEVES, 2000, p. 879, [grifo nosso]).

No exemplo (1), finalmente, encontra-se uma relativa referência de muito embora, que coloca toda a oração concessiva em uma posição mais tópica, ou seja, mais conhecida do interlocutor. Para ilustrar a posição mais tópica, a autora usa um exemplo com o embora (cf. tab. 1), porém inclui o muito: muito embora.

Perini (2006, p. 139) trata dos conectores, mas não especificamente dos concessivos, afirmando que "sua função é a de inserir uma oração (a subordinada) dentro de outra oração (a principal)”. Diferentemente, Azeredo (2000) descreve como o conector subordinativo é observado através do uso. O embora vai funcionar como uma oposição à ação do que se espera: "a conjunção concessiva esvazia a força causal ou argumentativa do fato que ela anuncia, de modo que o conteúdo da oração principal passa a representar o contrário do que se espera" (AZEREDO, 2000, p. 238).

Na última subseção, que trata dos advérbios, mais especificamente do advérbio de intensidade muito, Perini (2006) diz que ele é utilizado como intensificador ou adjunto circunstancial. Conforme Azeredo (2000, p. 143), "chama-se advérbio a palavra invariável que serve de núcleo a um sintagma adverbial [...]".

De acordo com Neves (2000, p. 233), "de um ponto de vista morfológico, o advérbio é uma palavra invariável". Analisando o advérbio através da perspectiva sintática, a autora menciona, na parte referente aos advérbios de intensidade, o muito que acompanhado da conjunção embora formam um único conector, como destaca Neves (2000) a seguir:

do ponto de vista sintático, ou relacional, o advérbio é uma palavra periférica, isto é, ele funciona como um satélite de um núcleo.

O advérbio (ou locução adverbial) atua nas diversas camadas do enunciado.

Revista Leitura V.2 nº 56 - jul/dez 2015 - Número regular - Autor/a: Vanessa Pereira Abreu - p. 153 - 172. 
O advérbio é periférico em um sintagma, incidindo sobre o seu núcleo (um constituinte), que, conforme a subclasse do advérbio que esteja em questão, pode ser [...] a conjunção embora (NEVES, 2000, p. 234235).

No capítulo destinado aos advérbios, Neves (2000, p. 235) apresenta um exemplo interessante do advérbio muito como satélite do núcleo que é a conjunção embora:

(2) Alguns inquéritos solicitados pelo Saps à polícia arrastam-se morosamente sem chegar à apuração policial dos crimes, muito embora as autoridades da mais alta hierarquia se empenhem nisso [grifo do autor].

No exemplo (2), o advérbio muito está no contorno da oração concessiva, incidindo sobre o seu núcleo, a conjunção embora. Na amostra investigada nesta pesquisa, encontram-se dados como:

(3) Não conseguiu, porém, ser dispensado da disciplina Bioestatística constante do currículo pleno do curso de destinação, muito embora houvesse tentado demonstrar, sem êxito, que a mesma estaria abrangida por Cálculo I ou por Biologia, matérias do currículo mínimo já cursadas na escola de origem [grifo nosso].

Portanto, pode-se afirmar que, de todas as gramáticas (normativas e de uso) consultadas para a realização desta pesquisa, somente a de Neves (2000) faz alguma referência ao fenômeno linguístico muito embora. Apesar de Azeredo (2000), Neves (2000) e Perini (2006) apresentarem gramáticas voltadas para o uso, não abordam o muito embora, quando tratam dos conectores concessivos.

\section{Pesquisa de Felício (2008) e Margarido (s/d)}

Felício (2008) apresenta o seguinte dado:

(4) e despois de auer ia nove dias que aquy estauamos, nos fomos despedir della, \& beijandolhe a mão nos disse: certo que me pesa de vos yrdes tão cedo, mas já que he forçado ser assim, ydeuos muyto embora, \& seja em boa hora a vossa tornada à Índia, que quando lá chegardes vos recebão os vossos como o antifo Salamão recebeo a nossa Raynha Sabaa na casa admirauel de sua grandeza. $(15 \mathrm{~F}, 22)$ (FELÍCIO, 2008, p. 135, [grifo nosso]).

Revista Leitura V.2 nº 56 - jul/dez 2015 - Número regular - Autor/a: Vanessa Pereira Abreu - p. 153 - 172. 
Conforme se pode destacar no exemplo anterior, pelo menos desde o século XV, já existia o muito embora. Conforme Felício (2008, p. 136), "a presença do intensificador muito diante de embora reforça a leitura temporal do item". Isto quer dizer que, na atualidade, o muito integra um único conector, juntamente com o embora.

De acordo com Felício (2008), no século XIX, o muito embora ocupa uma posição adverbial, usada no final, como a autora destaca no exemplo a seguir:

(5) E lógica tambem: mas duma lógica sancta, sentida e quente como o seio das mães, como o coração dos amantes. Não é o methodo da sciencia? é o methodo da vida! E a sciencia, se o desprazer, será scientifica muito embora, mas não será viva nem humana.... (19CAQ, 28) (FELÍCIO, 2008, p. 154-155, [grifo nosso]).

Desse modo, pode-se perceber que o muito embora estaria percorrendo, em épocas distintas, o mesmo caminho do embora: de advérbio no século XV para conjunção no século XIX, como Felício (2008) comenta no trecho a seguir:

embora apresenta o valor adverbial, devido às suas características sintáticas, como: posição na sentença e a presença do advérbio muito, intensificando o item. $\mathrm{O}$ valor concessivo é favorecido pelo contexto adversativo em que o advérbio é usado, já que há possibilidade de mudança na ordem da conjunção [...] (FELÍ́CIO, 2008, p. 155).

Já Margarido (s/d) faz menção ao conector quanto à posição que o mesmo ocupa dentro do enunciado, ou seja, as orações/construções concessivas, como hipotáticas adverbiais, podem ocupar três diferentes posições: intercalada, anteposta e posposta. De acordo com Decat (1993 apud MARGARIDO, s/d), a anteposição dos segmentos concessivos facilita a função de guia, sendo que o conteúdo do segmento concessivo orienta para o conteúdo da oração nuclear ${ }^{9}$. Margarido (s/d) ainda cita que a posposição do segmento concessivo, às vezes, se assemelha a um adendo. Já na posição de intercalação, Zamproneo (1998 apud MARGARIDO, s/d) afirma que essa posição auxilia no mecanismo de topicalização de um elemento da oração principal. Além disso, na intercalada, que "normalmente se coloca entre o sujeito e o verbo, pode-se dizer, provavelmente, que ocorre um processo de topicalização" (MARTELOTTA, 1998, p. 47).

\footnotetext{
${ }^{9}$ Dá-se o nome de "oração nuclear" ao que se denomina "oração principal” da gramática tradicional. Revista Leitura V.2 n 56 - jul/dez 2015 - Número regular - Autor/a: Vanessa Pereira Abreu - p. 153 - 172.
} 
(6) - Temos - muito embora sem perder a esperança de que mais uma vez se encontrará forma de fugir à catástrofe - de agir dentro de um rigoroso espírito de prudência e decisão (MARGARIDO, s/d, [grifo nosso]).

Conforme Margarido (s/d), o conector concessivo embora, por causa do estágio de gramaticalização em que se encontra, pode vir antecedido pelo advérbio muito, que o intensifica. A autora ainda comenta que, dependendo do lugar que o conector concessivo ocupa no enunciado, pode mudar o seu desempenho dentro do discurso.

Margarido (s/d) faz uma comparação das construções concessivas com o embora e das adversativas com o mas, respectivamente, demonstrando que as mesmas podem apresentar, algumas vezes, valores próximos na organização da informação dentro do enunciado, ou seja, o usuário da língua vai adaptando os conectores de acordo com suas necessidades particulares.

Por fim, vale destacar que o muito embora é considerado um conector com valor de oposição por Köche, Boff e Marinello (2011). Para essas autoras, determinados conectores são favorecidos pelo gênero textual do argumentar e do expor, estando o muito embora listado ao lado de outros de significação afim: "mas, porém, contudo, todavia, entretanto, no entanto, embora, muito embora, apesar de, não obstante, ao contrário etc" (KÖCHE, BOFF, MARINELLO, 2011, p. 104).

\section{Referencial teórico}

Nesta seção, destacam-se as principais concepções dos autores que seguem a teoria de vertente funcionalista de Givón (2012[1979]), dentre eles Kenedy e Martelotta (2003), Martelotta (1998), Castilho (2012) e Cezario (2012). De acordo com Givón (2012 [1979]),

a modelagem formal do fenômeno sob investigação é uma ferramenta antiga e útil na ciência. Em essência, um modelo formal não é nada além de uma reafirmação dos fatos em um nível mais compacto de generalização. [...] 1.0 modelo formal deve fazer asserções suficientemente poderosas de modo a acomodar todos os dados. 2. O modelo formal não deve fazer asserções poderosas demais que não sejam garantidas pelos dados (GIVÓN, 2012 [1979], p. 17-18).

Revista Leitura V.2 nº 56 - jul/dez 2015 - Número regular - Autor/a: Vanessa Pereira Abreu - p. 153 - 172. 
Givón (2012[1979]), quando fala sobre a modelagem formal, reforça a importância de uma teoria que ofereça hipóteses explicativas acerca de um determinado fenômeno linguístico. As generalizações devem estar ancoradas em dados reais de uso. Dessa forma, como a língua "é um instrumento de comunicação, então é inadequado tentar entender sua estrutura sem referência ao contexto comunicativo e à função comunicativa" (GIVÓN, 2012[1979], p.49).

Kenedy e Martelotta (2003, p. 20) ainda completam que a língua, "[...] como tal, não pode ser analisada como um objeto autônomo, mas como uma estrutura maleável, sujeita a pressões oriundas das diferentes situações comunicativas, que ajudam a determinar sua estrutura gramatical".

Assim como Kenedy e Martelotta (2003), Castilho (2012, p. 22) apresenta três postulados referentes à língua, a saber: “i) a língua é uma competência comunicativa; ii) as estruturas linguísticas não são objetos autônomos; iii) a explicação linguística deve ser procurada nos usos linguísticos e numa percepção pancrônica ${ }^{10}$ da língua”. De acordo com o primeiro postulado, estratégias linguísticas devem se adequar à interação comunicativa entre os usuários; conforme o segundo, as estruturas linguísticas precisam ser descritas e explicadas tendo como referência o contexto comunicativo; e, segundo o terceiro postulado, a explicação linguística deve advir do uso da língua e também de uma abordagem diacrônica e sincrônica.

De acordo com Cezario (2012, p. 19), “a abordagem funcionalista estuda a estrutura gramatical inserida na situação real de comunicação, considerando o objetivo da interação, os participantes e o contexto discursivo". Nessa perspectiva, o funcionalismo abrange uma série de fatores que devem ser levados em consideração quando se estuda uma língua, pois a língua não é estática.

Conforme Givón (1995 apud KENEDY e MARTELOTTA, 2003, p. 26), a visão funcionalista da linguagem se caracteriza pelas seguintes premissas: "a linguagem é uma atividade sócio-cultural; a estrutura serve a funções cognitivas e comunicativas; [...]; mudança e variação estão sempre presentes; [...]; a estrutura é maleável e não rígida; as gramáticas são emergentes; [...]”.

Givón (1995) apresenta a premissa, que diz respeito à linguagem, esta propriedade serve para estabelecer vínculo comunicativo entre os falantes, dos quais

\footnotetext{
${ }^{10}$ Nesta pesquisa, não há uma investigação pancrônica (ainda que seja importante), mas uma investigação a partir de dados sincrônicos.

Revista Leitura V.2 nº 56 - jul/dez 2015 - Número regular - Autor/a: Vanessa Pereira Abreu - p. 153 - 172.
} 
utilizam conhecimentos cognitivos para estabelecer diálogo. Outra premissa trata da mudança diacrônica observada em algumas palavras ao longo do tempo, levando em conta que a estrutura é maleável, adaptando-se ao contexto em que a mesma está inserida, sendo seu uso negociável na interação social.

Nesse sentido, de acordo com Givón (1995; 2012[1979]), o discurso é construído na própria interação comunicativa. No tratamento das orações concessivas, observa-se uma correlação entre processos mentais, discurso e comunicação (GIVÓN, 1995, 2012[1979]). As informações, negociadas na interação comunicativa, são constantemente reorganizadas, considerando como o falante/escritor avalia seu próprio discurso e como ele avalia e/ou atribui inferências ao ouvinte/leitor. Na medida em que o remetente se vale de uma oração/construção concessiva, está atribuindo possíveis inferências ao ouvinte/leitor. No caso especificamente do texto escrito, ambiente de análise dos dados desta pesquisa, o escritor projeta inferências ao potencial leitor e cancela-as de antemão, por meio do embora e do muito embora.

\section{Procedimentos metodológicos}

A metodologia adotada, em caráter quantitativo e qualitativo, centrou-se na busca do muito embora no site do Córpus Brasileiro da PUC de São Paulo, que apresenta $3.734^{11}$ dados para a construção em análise. O mesmo foi escolhido porque constitui o maior córpus online no Brasil e oferece a possibilidade de optar por uma tipologia ou gêneros específicos. Como não foi possível realizar a busca por determinados gêneros, os dados foram recolhidos aleatoriamente. Além disso, também não foi possível verificar a data dos dados em questão.

Foram analisados 50 dados do muito embora e comparados com 50 dados do embora, para observar como se comportam no que se refere aos seguintes critérios: posição do conector subordinativo concessivo em relação à oração principal, presença ou ausência de verbo e forma do verbo (forma conjugada ou forma nominal). Esses parâmetros morfossintáticos que norteiam a análise dos dados também já foram utilizados por Felício (2008).

\footnotetext{
${ }^{11}$ A última consulta ao site ocorreu no dia 15/12/2014 às 19 h. Revista Leitura V.2 nº 56 - jul/dez 2015 - Número regular - Autor/a: Vanessa Pereira Abreu - p. 153 - 172.
} 
Foram investigados os primeiros 50 dados de cada conector. Foram descartados dados que não apresentavam condições de análise por apresentarem uma grafia com problemas, por não terem algumas letras, por exibirem problemas com relação à acentuação $^{12}$ e à pontuação ou por serem enunciados repetidos. Também foram descartados os dados que apresentavam o verbo IR + o conector embora, como, por exemplo: "Eu já devia ter ido embora em dezembro do ano passado", por não se tratar de um conector concessivo, mas um advérbio de lugar.

\section{Análise dos dados}

Conforme mencionado, os dados serão analisados de acordo com os seguintes critérios: posição da oração/construção concessiva em relação à principal, presença ou ausência do verbo e forma do verbo. A seguir, os dados com o muito embora e o embora estão distribuídos em tabelas que concentram resultados referentes aos três critérios.

\section{Posição do conector subordinativo concessivo}

Com relação a esse critério, foram consideradas (i) posição anteposta (dados 7 e 8), (ii) posição intercalada (dados 9 e 10) e (iii) posição posposta (dados 11 e 12), conforme ilustram, respectivamente, cada par de dados, um com muito embora e outro com embora.

(7) E, muito embora configure prática pedagógica corrente, o tema não tem sido trazido às pautas de discussão e análise no âmbito da própria escola fundamental, que o abriga, tampouco de pesquisas no campo $\mathrm{O}$ da educação.

(8) Os juízes concluíram que, embora a lei não fale em estabilidade no emprego para doentes incuráveis, a Constituição protege a relação empregatícia contra despedida arbitrária ou sem justa causa.

(9) A orientação geral do projeto, muito embora nele se conserve a denominação de ensino normal rural, é a de elevação dos estudos no sentido de cultura geral.

(10) Os romanos quanto aos latinos, embora tenham sido influenciados pelos gregos, revelaram muitas peculiaridades em seu modo de escrever.

\footnotetext{
${ }^{12}$ As letras acentuadas nas palavras no interior do enunciado apresentavam símbolos em seus lugares, como, por exemplo: quadrados ou losangos, dificultando, assim, o entendimento de alguns vocábulos. Revista Leitura V. 2 n$^{\circ} 56$ - jul/dez 2015 - Número regular - Autor/a: Vanessa Pereira Abreu - p. 153 - 172.
} 
(11) O bom professor deve demonstrar que sabe o que quer e como quer, $\underline{\text { muito }}$ embora não deva usar de procedimentos coercitivos, como se fazia na escola tradicional.

(12) O acádio, ao contrário do árabe, tem plurais quase sempre regulares (ou seja, não tem plurais quebrados), embora algumas palavras masculinas tenham plurais femininos.

Tabela.1: Uso do muito embora e embora quanto à posição em relação à oração principal

\begin{tabular}{|c|c|c|c|c|}
\hline \multirow{2}{*}{$\begin{array}{c}\text { ORAÇÃO/CONSTRUÇÃO } \\
\text { CONCESSIVA }\end{array}$} & \multicolumn{4}{|c|}{ CONECTORES } \\
\cline { 2 - 5 } & \multicolumn{2}{|c|}{ MUITO EMBORA } & \multicolumn{2}{c|}{ EMBORA } \\
\cline { 2 - 5 } & FREQ. / TOTAL & $\mathbf{\%}$ & FREQ. / TOTAL & $\%$ \\
\hline POSPOSTA & $40 / 50$ & 80 & $32 / 50$ & 64 \\
\hline INTERCALADA & $3 / 50$ & 6 & $14 / 50$ & 28 \\
\hline ANTEPOSTA & $7 / 50$ & 14 & $4 / 50$ & 8 \\
\hline TOTAL & $\mathbf{5 0 / 5 0}$ & $\mathbf{1 0 0}$ & $\mathbf{5 0 / 5 0}$ & $\mathbf{1 0 0}$ \\
\hline
\end{tabular}

$\mathrm{Na}$ tab. 1, os resultados parecem indicar que o muito embora está em uma posição um pouco mais rígida, ou seja, o conector permanece, na maioria das vezes, contemplando a posição posposta $80 \%$; diferentemente do embora, que ocorre $64 \%$ dos casos nessa mesma posição, apresentando uma maior flexibilidade do conector quanto à posição no enunciado.

De acordo com o exposto, os dados indicam que o muito embora parece estar assumindo o mesmo comportamento sintático reservado ao embora, ou seja, na posposição. Esses resultados confirmam o que Neves (2000, p. 878) já havia afirmado sobre as posições das orações concessivas, ou seja, que a posposição é a posição mais frequente. Dentre as demais posições, intercalada e anteposta, os resultados com o muito embora totalizam $20 \%$ e os com o embora, $36 \%$. Esses percentuais parecem indicar uma maior mobilidade sintática do embora, pois o mesmo transita, com mais frequência, pelas três diferentes posições que o muito embora.

Além disso, para ambos, a posição da construção concessiva mais frequente é a posposta, porém as posições anteposta e intercalada divergem em termos de freqüência.

\section{Presença ou ausência do verbo}

Revista Leitura V.2 nº 56 - jul/dez 2015 - Número regular - Autor/a: Vanessa Pereira Abreu - p. 153 - 172. 
Quanto a esse critério, foram consideradas (i) a presença do verbo (dados 13 e 14) e (ii) a ausência do verbo na oração/construção em que aparece o conector $^{13}$ (dado 15), conforme ilustram os respectivos dados com o muito embora e embora.

(13) Não conseguiu, porém, ser dispensado da disciplina Bioestatística constante do currículo pleno do curso de destinação, muito embora houvesse tentado demonstrar, sem êxito, que a mesma estaria abrangida por Cálculo I ou por Biologia, matérias do currículo mínimo já cursadas na escola de origem.

(14) Todavia, como o primeiro terço da gestação é a fase em que, quantitativamente, a retenção de minerais é mínima, a utilização de qualquer uma das estimativas não provocaria tantos prejuízos, uma vez que os animais estariam recebendo suprimento de minerais acima das suas exigências, taxa de deposição de minerais no início da gestação é pequena e, embora erros relativamente grandes sejam cometidos, nessa fase, seus efeitos na exigência total de minerais pouco significam.

(15) Apesar de a Constituição de 1988 ter reduzido o número de casos em que o governo federal pode intervir nos estados e os estados nos municípios, o instituto da intervenção ainda vigora, embora sujeito à aprovação legislativa.

Tabela 2: Uso do muito embora e embora quanto à presença e ausência de verbo

\begin{tabular}{|c|c|c|c|c|}
\hline \multirow{2}{*}{ ORAÇÃO/CONSTRUÇÃ } & \multicolumn{4}{|c|}{ CONECTORES } \\
\hline CONCESSIVA & MUITO EMBORA & \multicolumn{2}{c|}{ EMBORA } \\
\hline COM VERBO & FREQ. / TOTAL & \% & FREQ. / TOTAL & $\%$ \\
\hline SEM VERBO & $50 / 50$ & 100 & $39 / 50$ & 78 \\
\hline TOTAL & $0 / 50$ & 0 & $11 / 50$ & 22 \\
\hline & $\mathbf{5 0 / 5 0}$ & $\mathbf{1 0 0}$ & $\mathbf{5 0 / 5 0}$ & $\mathbf{1 0 0}$ \\
\hline
\end{tabular}

Esses resultados mostram que a presença de verbo é categórica sob o escopo do muito embora; ao contrário, o embora permite ocorrências sem verbo, o que deixa de configurar uma oração para configurar uma construção concessiva. Essas considerações parecem ir ao encontro do processo de gramaticalização no qual se encontra o embora (MARGARIDO, s/d). É provável que a forma aparentemente mais recente, o muito embora, ainda não esteja sendo atingida por esse processo.

Neves (2000) destaca o muito embora nas construções concessivas, e após, na parte dos advérbios de intensidade, dos quais a autora fala que o muito pode incidir sobre o seu núcleo que é o embora, por isso o advérbio muito mantém uma função mais relacional com a conjunção embora através do contexto do enunciado.

\footnotetext{
${ }^{13}$ Não foram encontrados dados de muito embora com ausência de verbo. Revista Leitura V.2 nº 56 - jul/dez 2015 - Número regular - Autor/a: Vanessa Pereira Abreu - p. 153 - 172.
} 


\section{Forma do verbo}

Com relação à forma do verbo, foram considerados os seguintes critérios: (i) conector + verbo no subjuntivo (dados 16 e 17), (ii) conector + verbo no indicativo ${ }^{14}$ (dado 18), (iii) conector + verbo no gerúndio (dados 19 e 20), (iv) conector + verbo no particípio $^{15}$ (dado 21) e (v) conector + verbo no infinitivo ${ }^{16}$ (dado 22), conforme ilustram os dados com o muito embora e embora.

(16) Esse exemplo concreto pode esclarecer a noção a ser adotada para o aperfeiçoamento profissional, muito embora já não estejamos aqui no plano das coisas materiais, mas, no plano moral, mais complexo.

(17) Um número relativamente pequeno de estados é responsável por um grande volume na redistribuição de recursos, embora haja uma certa redistribuição dos municípios ricos para os pobres .

(18) A opinião dos respondentes era de que aconselhamento terapêutico (87 \%) era mais adequado para telemedicina do que diagnóstico primário (23\%), muito embora a maioria aceita o princípio de fazer $(91 \%)$ ou receber $(94 \%)$ diagnóstico remoto.

(19) Essa descoberta fez com que ele que, até então dividira seu interesse entre a Filologia e a Matemática, optasse definitivamente pela última, muito embora mantendo um vivo interesse por Línguas e Literatura.

(20) Magda Floriana Damiani, no texto Discurso pedagógico e fracasso escolar, nos relata o resultado de uma pesquisa que, em seu momento inicial, identificou os fatores de risco do fracasso escolar e, no seu prosseguimento, através de Estudos de Caso realizados em duas escolas que, embora atendendo alunos com os mesmos fatores de risco, têm taxas de evasão e repetência contrastantes, levanta as possíveis causas apontadas para essas discrepâncias.

(21) A partir daí, passamos a ter a informação de que esse massacre aos nossos companheiros tem uma única razão de ser: a disputa no Senado, coincidindo com o momento em que o Senador Gerson Camata preparava sua saída, embora contornada.

(22) Em seu discurso de despedida, Angeloz fez uma dura crítica ao ministro da Economia, Domingo Cavallo, embora sem citá-lo nominalmente.

Tabela 3: Uso do muito embora e embora quanto à forma do verbo

\footnotetext{
${ }^{14}$ Não foram encontrados dados de embora com o verbo no indicativo.

${ }^{15}$ Não foram encontrados dados de muito embora com o verbo no particípio.

${ }^{16}$ Não foram encontrados dados de muito embora com o verbo no infinitivo.

Revista Leitura V.2 nº 56 - jul/dez 2015 - Número regular - Autor/a: Vanessa Pereira Abreu - p. 153 - 172.
} 


\begin{tabular}{|c|c|c|c|c|}
\hline \multirow{2}{*}{$\begin{array}{c}\text { ORAÇÃO/CONSTRUÇÃO } \\
\text { CONCESSIVA }\end{array}$} & \multicolumn{4}{|c|}{ CONECTORES } \\
\cline { 2 - 5 } & \multicolumn{2}{|c|}{ MUITO EMBORA } & \multicolumn{2}{c|}{ EMBORA } \\
\cline { 2 - 5 } & FREQ. / TOTAL & $\mathbf{\%}$ & FREQ. / TOTAL & $\%$ \\
\hline VERBO NO SUBJUNTIVO & $47 / 50$ & 94 & $34 / 39$ & 68 \\
\hline VERBO NO INDICATIVO & $2 / 50$ & 4 & $0 / 39$ & 0 \\
\hline VERBO NO GERÚNDIO & $1 / 50$ & 2 & $1 / 39$ & 2 \\
\hline VERBO NO PARTICÍPIO & $0 / 50$ & 0 & $3 / 39$ & 6 \\
\hline VERBO NO INFINITIVO & $0 / 50$ & 0 & $1 / 39$ & 2 \\
\hline TOTAL & $\mathbf{5 0 / 5 0}$ & $\mathbf{1 0 0}$ & $\mathbf{3 9 / 3 9}$ & $\mathbf{7 8}$ \\
\hline
\end{tabular}

Os dados indicam que o conector concessivo muito embora mostra um padrão previsto para o conector embora, em que os verbos que vêm após o conector estão no modo subjuntivo. Com exceção de 3 dados, todos os demais verbos estão no modo subjuntivo logo após o muito embora, seguindo o que prevê a gramática normativa quanto ao emprego do modo subjuntivo em orações concessivas. Os resultados apontam para um percentual muito elevado de subjuntivo, ou seja, 94\%, praticamente um uso categórico. Esses números podem ser fortemente influenciados pelo fato de concessivas serem construções restritas à escrita ou fala mais formal, sendo frequentemente substituídas por adversativas. Pesquisas com dados de fala poderiam contribuir nesse sentido.

O embora, por sua vez, além de ocorrer sem verbo (cf. tab. 2), apresenta menos casos de uso com o subjuntivo (68\%) e uma combinação pouco mais acentuada com formas nominais: gerúndio, particípio e infinitivo em relação ao muito embora. Esse comportamento parece sinalizar para uma diversidade de relações, em decorrência, provavelmente, de um processo mais acelerado de perda de restrições sintáticas.

O que diferencia ambos é que o muito embora apresenta $100 \%$ dos dados com a presença do verbo e 94\% com o verbo no subjuntivo apresentando dados com uma estrutura mais fixa. O embora, por sua vez, apresenta $78 \%$ dos dados com verbo e $68 \%$ no modo subjuntivo, revelando uma certa diferença.

\section{Componente pragmático}

Nesta subseção, serão retomados dois dados já apresentados para que sejam analisados sob o viés do componente pragmático. Na interação comunicativa, na pragmática, o escritor constrói, a partir da organização do discurso, cenas na mente do Revista Leitura V.2 n 56 - jul/dez 2015 - Número regular - Autor/a: Vanessa Pereira Abreu - p. 153 - 172. 
potencial leitor. Com receio de que determinadas inferências possam ser derivadas, o escritor usa o muito embora e o embora como recursos de relativização. Vejamos os dados a seguir.

(23) O bom professor deve demonstrar que sabe o que quer e como quer, $\underline{\text { muito }}$ embora não deva usar de procedimentos coercitivos, como se fazia na escola tradicional.

(24) Magda Floriana Damiani, no texto Discurso pedagógico e fracasso escolar, nos relata o resultado de uma pesquisa que, em seu momento inicial, identificou os fatores de risco do fracasso escolar e, no seu prosseguimento, através de Estudos de Caso realizados em duas escolas que, embora atendendo alunos com os mesmos fatores de risco, têm taxas de evasão e repetência contrastantes, levanta as possíveis causas apontadas para essas discrepâncias.

Em (23), a informação de que o bom professor deve demonstrar que sabe o que quer e como quer poderia desencadear uma inferência de que o professor está livre para agir da forma como desejar ou julgar ser a mais apropriada. No entanto, tencionando desfazer essa possível inferência do leitor, o escrito insere, em seu discurso, uma oração introduzida pelo muito embora, na tentativa de relativizar a assertiva. Isso quer dizer que o professor deve demonstrar que sabe, porém não o pode fazer sem restrição: ele não deve usar de procedimentos coercitivos.

Em (24), uma pesquisa identificou fatores de risco associados ao fracasso escolar. Essa informação poderia fazer pressupor que, havendo esses fatores de risco, haveria mais incidência de evasão e repetência. Como essa relação não deve ser estabelecida de forma irrestrita, o embora é utilizado para indicar que existem casos em que são observados fatores de risco, e as taxas de evasão e repetência não são elevadas.

A análise desses dados aponta, portanto, para um comportamento pragmático do muito embora alinhado ao do embora. Ambos são acionados pelo produtor do texto quando se faz necessária uma retificação, uma correção de uma inferência que pode ser derivada, equivocadamente, pelo leitor.

Considerando a pesquisa realizada, pode-se afirmar que, as hipóteses foram confirmadas: i) foi constatado que o uso do fenômeno linguístico muito embora foi abordado somente por Neves (2000); diferentemente, nas outras duas gramáticas de Azeredo (2000) e Perini (2006) e nas gramáticas normativas de Bechara (2009), Cegalla (2005) e Cunha e Cintra (2007), nada foi encontrado; ii) o muito embora ocorre

Revista Leitura V.2 nº 56 - jul/dez 2015 - Número regular - Autor/a: Vanessa Pereira Abreu - p. 153 - 172. 
preferencialmente na posposição $(80 \%)$ e apresenta um uso quase categórico de verbo no modo subjuntivo (94\%); iii) o muito embora compartilha da mesma propriedade do embora de ser usado para fazer objeções em relação a um ponto de vista; e iv) apesar das gramáticas normativas não fazerem menção ao muito embora, é possível considerálo como um conector, visto que este tem o comportamento morfossintático e pragmático semelhante ao conector embora, como foi visto nos dados analisados, bem como observado por Felício (2008) que mostra que a junção do muito com o embora formam um único conector e por Köche, Boff e Marinello (2011).

Conforme os princípios funcionalistas de Givón (2012 [1979], p.49), a língua é um "instrumento de comunicação" e as generalizações devem estar ancoradas em dados reais de uso. Os dados apresentados neste trabalho são fruto de discursos transcritos de situações reais. O funcionalismo também transparece nos postulados de Castilho (2012), através da descrição do fenômeno linguístico no contexto em que está inserido e do uso do muito embora nas diversas situações transcritas no Córpus. E para finalizar, através da teoria funcionalista embasada nas palavras de Margarido (s/d) e de Martelotta (1998), pode-se detectar as posições posposta, intercalada e anteposta dentro dos dados coletados no Córpus.

\section{Considerações finais}

$\mathrm{Na}$ introdução deste trabalho, foi apresentado um objetivo, o qual foi alcançado. Consiste em investigar o uso do muito embora confrontando-o com o embora através da teoria funcionalista de vertente norte-americana, considerando os princípios funcionalistas de Givón (2012 [1979]) e de autores como Kenedy e Martelotta (2003), Martelotta (1998), Castilho (2012) e Cezario (2012).

Conforme as questões levantadas, ao longo desta pesquisa, pode-se notar que elas se confirmam. Na primeira questão, apesar do uso do muito embora parecer ser recorrente, as gramáticas normativas ainda não reconhecem esse fenômeno linguístico como conector (BECHARA, 2009; CEGALLA, 2005; CUNHA; CINTRA, 2007), mas as de uso já estão mudando esse conceito, porque trabalham com o princípio de uso real da linguagem e por isso analisam fenômenos linguísticos descritos por usuário da língua materna. O exemplo disso está na obra da Neves (2000), que traz definições para esse fenômeno, referindo-se ao mesmo como construção concessiva anteposta e topicalizada, ou, ainda, afirmando que o advérbio muito é periférico e funciona como o núcleo do Revista Leitura V.2 nº 56 - jul/dez 2015 - Número regular - Autor/a: Vanessa Pereira Abreu - p. 153 - 172. 
sintagma, acrescentado da conjunção embora. Já a segunda questão mostra que o muito embora tem o mesmo comportamento na construção de sua estrutura, pois apresenta-se o conector seguido do verbo, além disso, na maioria dos casos, este, vem no modo subjuntivo, assim como acontece no embora. Na terceira questão, pode-se observar que o muito embora assume a mesma posição do embora dentro do enunciado, ou seja, se o interlocutor fala sobre uma ação na oração principal, na oração/construção concessiva ela abre uma concessão, mas nada impede que ela continue a ser realizada. E, finalmente, a quarta questão em que através desta pesquisa foi afirmado que o muito embora é um conector, portanto seu emprego funciona da mesma maneira que o embora.

A teoria funcionalista de Givón (2012[1979]), reproduzida em Kenedy e Martelotta (2003), Martelotta (1998), Castilho (2012) e Cezario (2012), ilustra a forma como eles percebem a língua através do uso interativo entre os falantes. Essa concepção contribuiu na escrita deste trabalho, pois pode-se perceber o quanto a língua é complexa em sua essencialidade, trazendo para seus estudiosos o prazer de desvendá-la.

Para ultimar as considerações finais, espera-se que este trabalho possa contribuir com os estudos teóricos futuros sobre o uso do conector subordinativo concessivo muito embora, pois parece não haver pesquisas disponíveis sobre esse tema.

\section{Referências bibliográficas}

AZEREDO, José Carlos. Fundamentos de gramática do português. Rio de Janeiro: Jorge Zahar Ed., 2000.

BECHARA, Evanildo. Moderna gramática portuguesa. 37.ed. Rio de Janeiro: Nova Fronteira, 2009.

CASTILHO, Ataliba Teixeira de. Funcionalismo e gramáticas do português brasileiro. In: Funcionalismo linguístico: novas tendências teóricas. São Paulo: Contexto, 2012.

CEGALLA, Domingos Paschoal. Novíssima gramática da língua portuguesa. 46.ed. São Paulo: Companhia Editora Nacional, 2005.

CEZARIO, Maria Maura. Efeitos da criatividade e da frequência de uso no discurso e na gramática. In: Funcionalismo linguístico: análise e descrição. São Paulo: Contexto, 2012.

Revista Leitura V.2 nº 56 - jul/dez 2015 - Número regular - Autor/a: Vanessa Pereira Abreu - p. 153 - 172. 
CUNHA, Celso; CINTRA, Lindley. Nova gramática do português contemporâneo. 4.ed. Rio de Janeiro: Lexikon Editora Digital, 2007.

ESSARTS, Júlio César Berchon Des. Manifestações populares. Jornal Agora, Rio Grande, 20 jun. 2013. Carta do Leitor, p. 2.

FELÍCIO, Carla Patrícia. A Gramaticalização da conjunção concessiva embora. 2008, 180f. Dissertação (Mestrado em Estudos Linguísticos - Área de Concentração em Análise Linguística) - Instituto de Biociência, Letras e Ciências Exatas, Universidade Estadual Paulista, São José do Rio Preto, 2008.

GIVÓN, Talmy. A compreensão da gramática. São Paulo: Cortez; 2012 [1979]. Functionalism and grammar. Amsterdam/Philadelphia: John Benjamins, 1995.

KENEDY, Eduardo; MARTELOTTA, Mário Eduardo. A visão funcionalista da linguagem no século XX. In: Linguística funcional: teoria e prática. Rio de Janeiro: DP\&A / Faperj, 2003, p. 17-28.

KÖCHE, Vanilda Salton; BOFF, Odete Maria Benetti; MARINELLO, Adiane Fogali. Leitura e produção textual: gêneros textuais do argumentar e do expor. Petrópolis: Vozes, 2011.

MADEIRA, Fabio. Crenças de professores de Português sobre o papel da gramática no ensino da Língua Portuguesa. Linguagem e Ensino, Pelotas, v. 8, n. 2, p. 17-38, jul./dez. 2005 .

MARGARIDO, Renata. Construções adversativas e construções concessivas: semelhanças e contrastes. Centro de Comunicação e Letras - Universidade Presbiteriana Mackenzie, São Paulo: s/d.

MARTELOTTA, Mário Eduardo. Gramaticalização e graus de vinculação sintática em cláusulas concessivas e adversativas. Veredas: revista de Estudos Linguísticos, Juiz de Fora, v. 2, n. 3, p. 37-56, 1998. Disponível em: < http://www.ufjf.br/revistaveredas/files/2009/12/artigo34.pdf > Acesso em: 29 mar. 2014.

NEVES, Maria Helena de Moura. Gramática de usos do português. São Paulo: UNESP, 2000 .

PERINI, Mario A. Gramática descritiva do português. 4.ed. São Paulo: Ática, 2006.

Revista Leitura V.2 nº 56 - jul/dez 2015 - Número regular - Autor/a: Vanessa Pereira Abreu - p. 153 - 172. 